cold, very soluble in hot glacial acetic acid; essentially insoluble in water, or benzene, even if hot.

The thioureide was prepared by heating piperonyloin with an excess of ammonium thiocyanate in a sealed tube to $170^{\circ}$. The crystals obtained in this way were washed with cold water and purified by crystallization from hot methyl alcohol.

The analyses gave $8.6 \mathrm{I}$ and 8.50 per cent. $\mathrm{S}$; calculated for $\mathrm{C}_{17} \mathrm{H}_{12} \mathrm{O}_{4} \mathrm{~N}_{2} \mathrm{~S}, 9.4 \mathrm{I}$; for $\mathrm{C}_{17} \mathrm{H}_{14} \mathrm{O}_{5} \mathrm{~N}_{2} \mathrm{~S}, 8.99$.

The analyses cannot distinguish between the two formulas, and we are inclined to adopt the first in spite of the fact that it agrees less well with the percentages found than the second, since this formula is analogous to that of the ureide, and the difference in results might be caused by a little of some impurity, which could not be removed from the small amount. of substance at our disposal.

Properties.-The thioureide crystallizes in long, felted, nearly white needles, which decompose near $260^{\circ}$; slightly soluble in ethyl alcohol, methyl alcohol, acetone, or glacial acetic acid, when cold; moderately soluble in hot methyl alcohol, or carbon disulphide; very soluble in pyridine; insoluble in water.

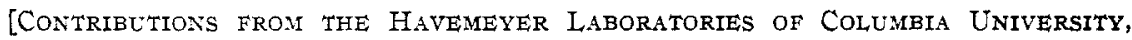
No. 182.$]$

\title{
SOME DERIVATIVES OF p-AMINOBENZONITRILE.
}

BY MARston TAYLOR BOgert and Lours ElsBerg Wise.

Reccived September 11, 1910.

In rgo3, Bogert and Kohnstamm ${ }^{1}$ published a brief article on $p$-aminobenzonitrile, giving its method of preparation and properties, and describing also its acetyl and propionyl derivatives.

The present paper is a continuation of this work. In it are described improved methods for the production of the $p$-nitro- and $p$-aminobenzonitriles and of the acetyl derivative of the latter, as well as certain new substances.

By the action of glacial formic acid, of benzoyl chloride, and of benzenesulphonyl chloride, upon the aminonitrile, the corresponding acyl derivatives were obtained, while with oxalic esters, cyano-oxanilic esters and cyano-oxanilide were secured. The acetaminonitrile yielded the acetaminobenzamide with alkaline hydrogen dioxide, and the $m$-nitro$p$-acetaminobenzonitrile on direct nitration. By reduction of the latter, the 3,4-diaminobenzonitrile was prepared, a most interesting orthodiamine.

The work is being continued and another paper will appear shortly. The fact that other chemists are working in closely related fields, or are

1 This Journai, 25, 478 (I903) 
approaching this field from other directions, has made it seem to us advisable to publish this preliminary paper.

\section{Experimental.}

$p$-Nitrobenzonitrile, (4) $\mathrm{O}_{2} \mathrm{~N} \cdot \mathrm{C}_{6} \mathrm{H}_{4} \cdot \mathrm{CN}(\mathrm{I})$, is best prepared by the wellknown Sandmeyer method ${ }^{1}$ from pure $p$-nitroaniline. It may be prepared also from the commercial "Nitrosamine" paste.

The latter, placed at our disposal through the courtesy of the Badische Company, contains about 25 per cent. of the sodium salt of $p$-nitrophenylnitrosamine mixed with the necessary amount of nitrite ${ }^{2}$ and was converted into the diazo compound by mixing 60 parts of the paste with 200 parts cold (not over $18^{\circ}$ ) water, then adding 2 I parts dilute hydrochloric acid (about 30 per cent. $\mathrm{HCl}$ ) in a fine stream, stirring gently. This diazo solution was allowed to stand for about a half hour, with occasional gentle stirring, was filtered (from diazoamino compounds and other contaminants), and the filtrate added to the copper cyanide solution in the usual way. The temperature of the diazo solution must at no time rise above $18^{\circ}$. The crude nitronitrile was separated from mineral salts by extraction with boiling carbon tetrachloride. Orange crystals were thus obtained, which were still impure. The yield of these orange crystals varied from about 3 I to 43 per cent. of the theory. Further purification was effected by recrystallization from water, distillation with steam, or sublimation.

A much more satisfactory method is to distil the original crude nitrile direct with steam. The product thus obtained is practically pure (m. p. about $148^{\circ}$, cor.), and the yield about 50 per cent. of the theory if pure $p$-nitroaniline was used as the initial material.

The pure nitronitrile forms nearly colorless, fluffy crystals, melting

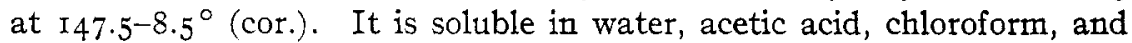
carbon tetrachloride, at their boiling points, volatil with steam, and can be sublimed. It has an odor recalling that of a mixture of nitrobenzene and benzonitrile.

$p$-Aminobenzonitrile, (4) $\mathrm{H}_{2} \mathrm{~N} . \mathrm{C}_{6} \mathrm{H}_{4} \cdot \mathrm{CN}(\mathrm{I})$. -The nitronitrile was reduced with stannous chloride and hydrochloric acid. ${ }^{3}$ It is important that a pure nitronitrile be used in this reduction, as it is not so easy to separate the aminonitrile from impurities, and the yield is thus considerably decreased. After reduction, no excess of concentrated hydrochloric acid was added, but the mixture was left in the refrigerator overnight, the separated tin double salt of the aminonitrile then filtered out, dissolved in cold water in a separatory funnel, ice and ether added, the solution

2 Bogert and Kohnstamm, This Journal, 25, 479 (1903).

${ }^{2}$ Ber., 27, 5 I4 (1894); U. S. Patents 531973, 531974, 531975, 531976 and 531977.

${ }^{3}$ Bogert and Kohnstamm, Loc cit.; Bogert and Hand, THrs Jourval, 24, I033 (1902); Bogert and Beans, Ibid., 26, 469 (1904). 
carefully made alkaline with dilute ice-cold sodium hydroxide solution, and the mixture well shaken. The ethereal layer was separated, and the extraction with ether repeated several times. The ethereal extracts were united and the ether driven off, leaving the aminonitrile in deeply colored crystals. Purified by recrystallization from water, it was obtained in colorless needles or long prisms. The best yield of aminonitrile was about $75^{-6}$ per cent. of the theory.

An attempt to prepare the aminonitrile by distilling a dry and intimate mixture of potassium cyanide and potassium sulphanilate proved unsatisfactory.

The pure aminonitrile forms colorless crystals, melting at $85.5^{-86^{\circ}}$ (cor.), as reported by Bogert and Kohnstamm. ${ }^{1}$

p-Formaminobenzonitrile, (4) $\mathrm{HCONH} . \mathrm{C}_{6} \mathrm{H}_{4} \cdot \mathrm{CN}(\mathrm{I})$, from the nitrile and glacial formic acid, was purified by repeated crystallization from water and decolorization with boneblack. It forms small colorless crystals, melting at $188-9^{\circ}$ (cor.) in a sealed tube.

Found: $N$, I9.3I. Calculated for $\mathrm{C}_{8} \mathrm{H}_{8} \mathrm{ON}$ : $\mathrm{N}$, I9.18.

$p$-Acetaminobenzonitrile, as stated, was described in the paper of Bogert and Kohnstamm. ${ }^{1}$ The following is a somewhat better method of preparation:

The aminonitrile is added gradually to an excess of hot acetic anhydride and the mixture heated for ten or twenty minutes. The excess of anhydride is then destroyed by the addition of water to the hot solution and, on cooling, the acetyl derivative crystallizes out practically pure. A small additional amount, less pure, may be recovered from the mother liquor. Yield, $77-85$ per cent. of the theory. Crystallized from water until the melting point remained constant, colorless needles were obtained, melting at $205.5^{\circ}$ (cor.). Bogert and Kohnstamm ${ }^{1}$ found an uncorrected melting point of $200^{\circ}$.

p-Acetaminobenzamide, $\quad \mathrm{CH}_{3} \mathrm{CONH} . \mathrm{C}_{6} \mathrm{H}_{4} \cdot \mathrm{CONH}_{2}$--p-Acetaminobenzonitrile was added to a solution of hydrogen dioxide made slightly alkaline with potassium hydroxide, and the mixture heated for half an hour or an hour at $100^{\circ}$. A clear yellow solution resulted. This was filtered hot and the filtrate allowed to cool. The amide which separated was recrystallized first from water and then twice from dilute alcohol. It forms colorless prisms, melting at about $274.5^{\circ}$, with preliminary softening and sublimation. Further crystallization did not alter this melting point or diminish sensibly the tendency to a preliminary drag and sublimation.

Found: N, I 5.95. Calculated for $\mathrm{C}_{2} \mathrm{H}_{10} \mathrm{O}_{2} \mathrm{~N}_{2}: \mathrm{N}$, i 5.73 .

Heated with potassium hydroxide solution, it is saponified with evolution of ammonia.

${ }^{1}$ Loc, cit. 


\section{3-Nitro-4-acetaminobenzonitrile,}

(4) $\mathrm{CH}_{3} \mathrm{CONH} . \mathrm{C}_{6} \mathrm{H}_{3}\left(\mathrm{NO}_{2}\right)(3) \mathrm{CN}(\mathrm{I})$. Five grams $p$-acetaminobenzonitrile were gradually stirred into a paste prepared by adding $6.7 \mathrm{~g}$. finely pulverized potassium nitrate to $30 \mathrm{cc}$. concentrated sulphuric acid, and the whole kept at a temperature of - IO ${ }^{\circ}$ to $O^{\circ}$ by a freezing mixture. After all the nitrile had been added, the mixture was held at about $0^{\circ}$ for an hour or two longer, and the sirupy mass then poured slowly upon cracked ice. After standing for a short time, the yellow precipitate was washed with water, a little very dilute ammonium hydroxide solution, and again with water. Without previous drying, it was added to warm acetic anhydride, the solution boiled for a few minutes, water added to destroy the excess of anhydride, and on cooling the nitrile separated in beautiful yellow prisms. Recrystallized from 95 per cent. alcohol, long, lustrous, pale-yellow needles were obtained, melting at $\mathrm{I} 3 \mathrm{I} .5^{\circ}$ (cor.), softening somewhat at $130^{\circ}$. Yield, about 64 per cent. of theory. The crystals are soluble in water or alcohol, less readily in benzene, and practically insoluble in carbon tetrachloride.

Found: $\mathrm{N}, 20.74$. Calculated for $\mathrm{C}_{8} \mathrm{H}_{7} \mathrm{O}_{3} \mathrm{~N}_{3}: \mathrm{N}, 20.49$.

The process just described must be followed closely to get a good yield of pure substance. We have tried various other methods of nitration, but none proved as satisfactory as the above.

To locate the nitro group, the nitroacetaminobenzonitrile was saponified by boiling it with alcoholic potassium hydroxide solution. During the boiling, ammonia was evolved and the solution turned purple. On cooling, orange needles separated, corresponding in properties to the description in the literature of potassium 3-nitro-4-aminobenzoate. The free acid liberated from this salt by the action of hydrochloric or sulphuric acid crystallized from dilute alcohol in orange-yellow needles which, carefully dried in vacuum and heated in a sealed tube, began to sublime at about $190-200^{\circ}$, forming a yellow coating on the sides of the tube. At $277^{-} 8^{\circ}$ (cor.), the sides of the tube began to clear, and at $290-1^{\circ}$ (cor.) the substance decomposed. Salkowski ${ }^{1}$ and Ritsert ${ }^{2}$ give the melting point of 3-nitro-4-aminobenzoic acid as $284^{\circ}$.

Found: $\mathrm{N}, 15.05$ and 15.27 . Calculated for $\mathrm{C}_{7} \mathrm{H}_{6} \mathrm{O}_{4} \mathrm{~N}_{2}, 15.39$.

As a further check on the correctness of the work, some 3-nitro-4-aminobenzoic acid was prepared according to the method of Ritsert ${ }^{3}$ by nitrating pure $p$-acetaminobenzoic acid, and the product was found to be identical with that obtained by the saponification of the above nitroacetaminobenzonitrile.

$p$-Benzoylaminobenzonitrile, $\mathrm{C}_{8} \mathrm{H}_{5} \mathrm{CONH} . \mathrm{C}_{6} \mathrm{H}_{4} . \mathrm{CN}$, from $p$-aminobenzo-

${ }^{1}$ Ann., I73, 54.

D. R. P., 151725 .

Loc, cit. 
nitrile and benzoyl chloride, in presence of sodium carbonate, was purifred by crystallization from dilute alcohol, after treating with boneblack. The pure substance melts at $170^{\circ}-170.5^{\circ}$ (cor.), with very slight previous softening.

\section{Found: $N$, 22.94 and 12.78 . Calculated for $\mathrm{C}_{14} \mathrm{H}_{10} \bigcirc \mathrm{N}_{2}: \mathrm{N}, \mathrm{I} 2.62$.}

p-Benzenesulphoneaminobenzonitrile, $\quad \mathrm{C}_{6} \mathrm{H}_{5} \mathrm{SO}_{2} \mathrm{NH} . \mathrm{C}_{6} \mathrm{H}_{4} \mathrm{CN}--p$-Aminobenzonitrile was heated for a few minutes with excess of benzenesulphone chloride. The crude product was washed with ether and crystallized from alcohol to constant melting point. Colorless arborescent crystals, melting at $175^{-6^{\circ}}$ (cor.), with very slight preliminary softening.

Found: $\mathrm{N}$, I0.90; $\mathrm{S}, \mathrm{1} 2.74$. Calculated for $\mathrm{C}_{13} \mathrm{H}_{10} \mathrm{O}_{2} \mathrm{~N}_{2} \mathrm{~S}: \mathrm{N}$, 10.85; S, I2.42.

Methyl p-Cyano-oxanilate, $\mathrm{CH}_{3} \mathrm{OCOCONH} . \mathrm{C}_{6} \mathrm{H}_{4} \cdot \mathrm{CN}$.-A mixture of 4 g. methyl oxalate and $1.5 \mathrm{~g}$. p-aminobenzonitrile was heated for three and a half hours at $110^{\circ}$. The crude product crystallized from methyl alcohol in nacreous leaflets, melting at $208.5-9.5^{\circ}$ (cor.).

\section{Found: $\therefore$, 14.O. Calculated for $\mathrm{C}_{10} \mathrm{H}_{8} \mathrm{O}_{3} \mathrm{~N}_{2}: \mathrm{N}, \mathrm{I}_{3} .73$.}

Ethyl $p$-Cyano-oxanilate, prepared similarly to the methyl ester, crystallizes from alcohol in small, nearly colorless, flat prisms, softening somewhat at $187^{\circ}$ (cor.), and melting at $188.5^{-9^{\circ}}$ (cor.).

Found: $\mathrm{N}$, I3. I3. Calculated for $\mathrm{C}_{12} \mathrm{H}_{10} \mathrm{O}_{3} \mathrm{~N}_{2}: \mathrm{N}, 12.85$.

Di-p-cyano-oxanilide, (p)NC. $\mathrm{C}_{6} \mathrm{H}_{4} \cdot \mathrm{NHCOCONH} \cdot \mathrm{C}_{6} \mathrm{H}_{4} \cdot \mathrm{CN}(p)$ - $\mathrm{A}$ mixture of equal parts by weight of $p$-aminobenzonitrile and ethyl oxalate was heated five and a half hours at $160-210^{\circ}$. Ethyl $p$-cyano-oxanilate was extracted from the crude product with alcohol, and the residual insoluble product dried and analyzed:

Found: $\mathrm{N}$, I9.33. Calculated for $\mathrm{C}_{13} \mathrm{H}_{10} \mathrm{O}_{2} \mathrm{~N}_{4}: \mathrm{N}$, I9.32.

The compound melts above $288^{\circ}$, and is insoluble or very difficultly soluble in water, alcohol, glacial acetic acid, ether, benzene, nitrobenzene, aniline, amyl alcohol or phenol.

3,4-Diaminobenzonitrile, $(3,4)\left(\mathrm{NH}_{2}\right)_{2} \mathrm{C}_{6} \mathrm{H}_{3}$. $\mathrm{CN}$--Five grams 3-nitro-4-acetaminobenzonitrile were added gradually to a solution of $35 \mathrm{~g}$. stannous chloride in $75 \mathrm{cc}$. concentrated hydrochloric acid at a temperature of $30-40^{\circ}$. Complete solution resulted, the deep yellow color gradually growing paler. Nothing separated from this solution even after standing in the refrigerator for several days. It was, therefore, poured into a separatory funnel, covered with a layer of ether, and carefully made alkaline by adding cold dilute sodium hydroxide solution. A voluminous precipitate appeared, not easily soluble in the ether. The mixture was repeatedly extracted with ether, the extracts combined, dried with calcium chloride, and the ether driven off. The colorless residue, dried in vacuum, rapidly turns pink in the air. Crystallized from water, it forms colorless needles, softening at $146^{\circ}$ and melting at $147.5^{\circ}$ (cor.). This melting 
point could not be changed by further recrystallization. The compound is soluble in boiling water, hot alcohol or boiling chloroform. but dissolves in ether with difficulty.

Found: N, 3I.64. Calculated for $\mathrm{C}_{7} \mathrm{H}_{7} \mathrm{~N}_{3}: \mathrm{N}, 3 \mathrm{I} .5^{8}$.

\section{DERIVATIVES OF CAMPHOROXALIC ACID. XIII. ${ }^{1}$}

By J. BISHop TINGLE AND S. J. Bates.

Received September 10, jgio.

In some of the earlier papers on this subject it has been pointed out that the condensation compounds of camphoroxalic acid and of its esters with amines may be formulated either as $\mathrm{C}_{8} \mathrm{H}_{24}<\mathrm{CO}: \mathrm{NHR}_{2} \mathrm{H}$ (alkyl) $\mathrm{C}_{8} \mathrm{H}_{14}\left\langle\left.\left.\right|_{\mathrm{CONR}} ^{\mathrm{CHCCO}}\right|_{2} \mathrm{H}(\mathrm{alkyl})\right.$. The balance of evidence being in favor of II.

the first of these formulas, it has been employed by the senior author and his colleagues in their publications.

The work described in the present communication had, for one of its objects, the accumulation of more direct positive proof of the constitution of the amino condensation compounds in question; we therefore directed our attention to the investigation of reactions which should show the presence of an imino - NHR, or hydroxyl $>\mathrm{C}(\mathrm{OH})$ - group in the condensation compounds

Our first experiments were carried out with phenylcamphoformeneaminecarboxylic acid, $\mathrm{C}_{8} \mathrm{H}_{14}\left\langle{ }_{\mathrm{CONHC}}^{\mathrm{C}}: \mathrm{CCO}_{6} \mathrm{H} \mathrm{H}_{5}\right.$;it is prepared very readily from camphoroxalic acid and aniline, is easy to purify and is relatively stable. We obtained it by a slight modification of the method described by the senior author and A. Tingle. ${ }^{2}$ The acid is attacked immediately by bromine, in chloroform solution; hydrobromic acid is evolved in quantity, 3,4-dibromoaniline hydrobromide is deposited in crystals and the solution contains camphoroxalic acid. The probable mechanism of this reaction appears to be the more simple on the assumption of the

1 The previous communications of this series have appeared as follows: Bishop Tingle, Inaug. Dissn., Munich, I889, p. 34; J. Chem. Soc., 57, 652 (1890); Am. Chem. $J$., 19, 393 (1897); 20, 318 (I898). Bishop Tingle and A. Tingle, Ibid., 21, 238 (I899); 23, 214 (1900). Bishop Tingle, This JournaI, 23, 363 (I90I). Bishop Tingle and W. E. Hoffmann, Amer. Chem. J., 34, 217 (1905). Bishop Tingle and C. J. Robinson, Ibid., 36, 223 (Ig06). Bishop Tingle, This Journal, 29, I242 (I907). Bishop Tingle and L. F. Williams, Amer. Chem. J., 39, 105, 277 (1908).

${ }^{2}$ Loc. cit. 